\title{
SECONDARY ABDOMINAL PREGNANCY: A CASE REPORT
}

\section{H. C. Savitha ${ }^{1}$, Sanjay Kumar C2, Rajashekar ${ }^{3}$, Deepthi H. R ${ }^{4}$}

\section{HOW TO CITE THIS ARTICLE:}

H. C. Savitha, Sanjay Kumar C, Rajashekar, Deepthi H. R. "Secondary Abdominal Pregnancy: A Case Report". Journal of Evolution of Medical and Dental Sciences 2014; Vol. 3, Issue 38, August 25; Page: 9790-9793, DOI: $10.14260 /$ jemds/2014/3268

ABSTRACT: Abdominal pregnancy is a rare and life threatening condition, it is associated with high morbidity and mortality if not recognized early and managed properly. Here we are presenting a case of secondary abdominal pregnancy with placental implants in broad ligament and uterine surface.

KEYWORDS: Abdominal pregnancy, ectopic pregnancy, tubal abortion and tubal rupture.

INTRODUCTION: Secondary abdominal pregnancies usually develop as a result of tubal abortion, tubal rupture, and uterine rupture with intra-abdominal implantation. The incidence of ectopic pregnancy in India is 3.86 per 1000 live births among all hospital reported pregnancies as per Indian Council of Medical Research task Force. Among these 95\% are tubal ${ }^{1}$ and $1-4 \%$ are abdominal. ${ }^{2}$

Abdominal pregnancy can be classified as 'primary' when implantation takes place outside the uterine adnexa and secondary when abdominal pregnancy follows an undetected tubal rupture. Almost all cases of abdominal pregnancy are secondary following early rupture or abortion of a tubal pregnancy into the peritoneal cavity. We are reporting a case of secondary abdominal pregnancy with placental implants over the broad ligament and posterior uterine surface.

CASE REPORT: A 22 years old lady presented to gynaec OPD at Mandya institute of medical sciences with h/o amenorrhea since 3 months with lower abdominal pain since 2 weeks, more over the right iliac fossa. She was Gravida2 para1 living1, had full term normal delivery 2 years back. There was no history of contraception usage.

On examination her general condition was good, vital signs were normal. Per abdomen examination revealed a tender mass of about $12 \times 10 \mathrm{~cm}$, cystic in consistency present over right iliac fossa. On per vaginal examination, uterus was anteverted, just bulky, deviated to left side. A cystic tender mass corresponding to 14 weeks gravid uterus size felt apart from uterus in right fornix. Ultrasound scanning revealed empty uterine cavity with single live ectopic gestation of 12 weeks on right side. Very minimal fluid was seen in the cul-de-sac.

Patient was posted for emergency laparotomy after doing relevant investigations and arranging 2 units of blood. Per operatively, organized clots of about $100 \mathrm{~g}$ was present adherent to bowel, omentum and bladder. Gestational sac along with a live fetus was found embedded in the pouch of Douglas. Placenta was attached to the posterior surface of the broad ligament and uterus. Left fallopian tube was edematous, right fallopian tube and both ovaries were normal. Uterus was intact.

Gestational sac with the live fetus which was lying in the pouch of Douglas got ruptured while removing from pouch of Douglas. Placenta and membranes attached to the posterior surface of uterus and broad ligament were separated and removed completely. Based on the laparotomy findings case was diagnosed as secondary abdominal pregnancy subsequent to tubal abortion, as the serosal 
surface of the fallopian tube appeared normal. Placenta had taken blood supply from the broad ligament and the uterus. 2 units of blood were transfused. Post-operative period was un- eventful.

Figure 1: Gestational sac with live fetus lying in pouch of douglas being removed.

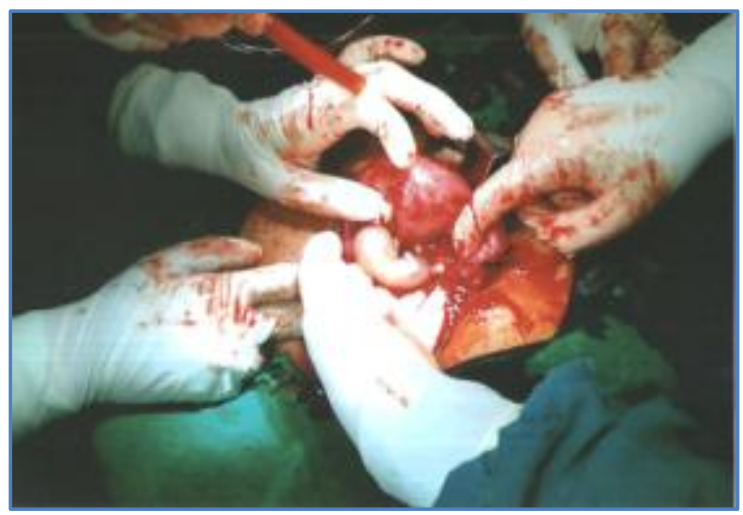

Fig. 1

DISCUSSION: Abdominal pregnancy is a rare and dangerous obstetric event which is associated with high maternal and fetal mortality. Maternal mortality ranges from 0 to $30 \% .^{3}$ The factors that increase the risk of ectopic pregnancy are history of pelvic inflammatory disease, chlamydial or gonococcal cervicitis, infertility, morphological tubal abnormality, previous tubal surgery, recent use of intra uterine contraceptive device and history of previous ectopic pregnancy.4

Clinical presentation varies with features of ruptured ectopic pregnancy during earlier gestation as compared to a term abdominal pregnancy with no definitive symptoms. Abdominal pregnancy may cause intestinal or ureteric obstruction, intra-abdominal hemorrhages. It may be further complicated by infection with abscess formation. Very rarely there is continuation of secondary abdominal pregnancy to term with delivery of a live fetus. ${ }^{5}$ The other cause for maternal death in patient with an abdominal pregnancy includes toxemias, anemia, pulmonary embolus and coagulopathy. ${ }^{6}$

The high rate of morbidity and mortality from abdominal pregnancy often results from a delay in diagnosis. The placenta can be attached to the uterine wall, bowel, mesentery, liver, spleen, bladder and ligaments. It can be detached anytime during pregnancy leading to torrential blood loss. ${ }^{7}$

Sonography is considered the front-line diagnostic method, but diagnosis requires a high level of suspicion as an abdominal pregnancy may be missed even on ultrasound. Magnetic resonance imaging can be useful to demonstrate the anatomic relationship between the placenta and invasion area in order to be prepared preoperatively for the possible massive blood loss.

It is general recommendation to perform a laparotomy when the diagnosis of abdominal pregnancy is made. ${ }^{8}$ Maternal deaths associated with abdominal pregnancy result from hemorrhage after inadvertent dislodgement of placenta. In our patient placenta was attached to the posterior surface of broad ligament and uterus. It was possible to remove whole of the placenta without significant hemorrhage.

Removal of entire placenta is recommended but if significant hemorrhage occurs, it is safer to leave all or part of placenta and allow it to absorb slowly. Indeed, post-operative use of methotrexate administration is controversial in the case of the placenta left in-situ. ${ }^{9}$ 


\section{CASE REPORT}

Figure 2: Showing fetus which is being removed from pouch of douglas.

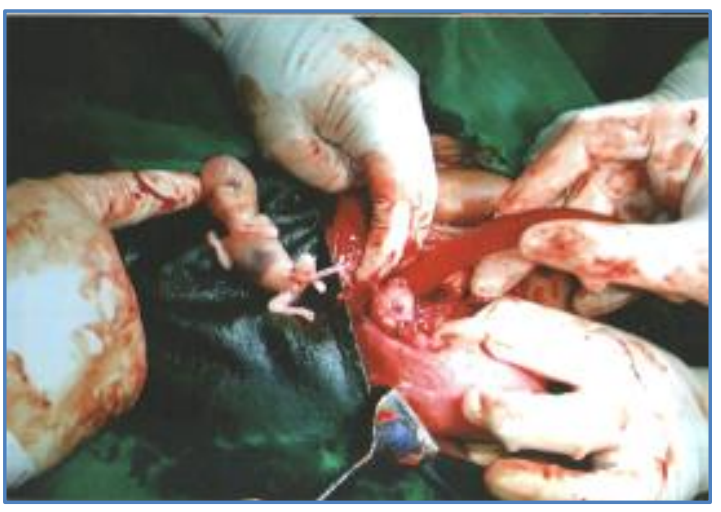

\section{Fig. 2}

CONCLUSION: Abdominal pregnancy in any form is associated with high mortality and morbidity. High index of suspicion is necessary in reproductive age group women presenting with pain abdomen and bleeding per vagina following a period of amenorrhea. Prompt diagnosis with effective management reduces morbidity and mortality. Ultrasound is mandatory in a patient with amenorrhea prior to $\mathrm{D} \& \mathrm{C}$, when urine pregnancy test is positive.

\section{REFERENCES:}

1. Cunningham FG, Gant NF, Leveno KJ et al (Eds). Williams's obstetrics $21^{\text {st }}$ edn. New York, McGraw Hill; 2001: 899.

2. Shaw HA, Ezenwa E. Secondary abdominal pregnancy in a Jehovah's Witness. South Med J 2000; 93: 898-900.

3. Martin JN, Mc Caul JF, Emergent management of abdominal pregnancy. Clin Obstet Gynecol. 1990; 33: 438-47. [PubMed].

4. Murray H, Baakdah H, Bardell T, Tulandi T. Diagnosis and treatment of ectopic pregnancy. CMAJ 2005,173: 905-912.

5. Sharma S, Kumar G. A rare case of viable 32 weeks secondary abdominal pregnancy. J Obstet Gynaecol India 2002; 52: 119-20.

6. Kun KY, Wong PY, Ho MW, Tai CM, Ng TK. Abdominal pregnancy presenting as a missed abortion at 16 weeks' gestation. Hong Kong Medical Journal 2000; 6: 425-7.

7. Ang LP, Tan AC, Yeo SH. Abdominal pregnancy: a case report and literature review. Singapore Med J 2000, 41:454-457.

8. King M, Bewes PC, Cairns J, Thornton J. Primary Surgery; Volume One: Non-trauma. Chapter 8, In: Abdominal pregnancy. Bonn University.

9. Worley KC, Hnat MD, Cunningham FG. Advanced extrauterine pregnancy: diagnostic and therapeutic challenges. Am J Obstet Gynecol 2008 Mar; 198 (3): 297.e1-7. 


\section{CASE REPORT}

\section{AUTHORS:}

1. H. C. Savitha

2. Sanjay Kumar C.

3. Rajashekar

4. Deepthi H. R.

\section{PARTICULARS OF CONTRIBUTORS:}

1. Associate Professor, Department of Obstetrics and Gynaecology, Mandya Institute of Medical Sciences, Mandya, Karnataka.

2. Assistant Professor, Department of Obstetrics and Gynaecology, Mandya Institute of Medical Sciences, Mandya, Karnataka.

3. Assistant Professor, Department of Surgery, Mandya Institute of Medical Sciences, Mandya, Karnataka.

4. Resident, Department of Obstetrics and Gynaecology, Mandya Institute of Medical Sciences, Mandya, Karnataka.

\section{NAME ADDRESS EMAIL ID OF THE} CORRESPONDING AUTHOR:

Dr. H. C. Savitha, Associate Professor, Department of Obstetrics and Gynaecology, MIMS, Mandya.

Email: drhcsavithamohan@gmail.com

Date of Submission: 11/08/2014.

Date of Peer Review: 12/08/2014.

Date of Acceptance: 20/08/2014.

Date of Publishing: 23/08/2014. 